\title{
Research on the Lifetime Estimation of Secondary Connections Using the PRP M/G/1 Queuing Network Model
}

\author{
Ekendeke Ndiomo Maurice Junior \\ Changchun University of Science and Technology \\ Changchun, China \\ maundio@yahoo.fr
}

\author{
Bin Guo \\ Changchun University of Science and Technology \\ Changchun, China \\ guobin@cust.edu.cn
}

\begin{abstract}
Allocated Spectrum band has always been a limited resource; being later a more challenging issue due to the growth of user demands. The past decade is marked by important changes in spectrum access through especially cognitive radio technology. Here, spectrum access issue can be studied in all the different aspects of cognitive capabilities. This paper focuses on spectrum handoff in spectrum mobility. We will then study secondary connections behaviors after multiple interruptions providing from multiple secondary connections. In the IEEE 802.22 standards [1], two Spectrum Handoff Sequences have been defined to characterize Secondary Connections behaviors after each Primary Connections interruption. These sequences are known as always-leaving and always-staying sequences. A recent analysis uses the extended data delivery time metric to analyze these Spectrum Handoff Sequences. It shows the exponential value of connections service time in the first sequence (always-leaving sequence) and in the other (always-staying sequence), the lack of fairness due to the acquisition of channel's low-priority queue by the ongoing secondary connection (i.e. the secondary connection actually being served in the low-priority queue). We've also noticed that the Extended Data Delivery Time is a good but limited metric because of the lack of prevision, which is a quality needed in cognitive radio networks, especially when implementing spectrum handoff sequences. Our present study aims to analyze these limitations. In what follows, we use the PRP M/G/1 queuing model in cognitive radio network to evaluate latency-sensitive traffic of Secondary Connections through a novel performance metric that we name Lifetime of Secondary Connections.
\end{abstract}

Keywords-cognitive radio; spectrum handoff; lifetime of secondary connection; queuing theory

\section{INTRODUCTION}

In Cognitive Radio system, Primary Connections have the preemptive right to use a specific spectrum while Secondary Connections have a lower priority on the use of the spectrum. So they are needed to use the spectrum without causing harmful interference. If the current spectrum band in use becomes unavailable, the spectrum mobility function is performed to provide a seamless transmission. Any environmental change during the transmission such as Primary Connections appearance, user movement, or traffic variation can trigger this adjustment. Efficient utilization can be improved by allowing a Secondary Connections to utilize a licensed band when primary user Primary Connections are absent
[2]. The efficiency also guarantees that the coming back of a Primary Connections will not interfere with the running Cognitive Radio system. One of the most efficient queuing model that helps analyze secondary and primary connections is the PRP M/G.1 queuing network model because it considers general service time distribution of the primary and secondary connections; different operating channels in multiple handoffs; and queuing delay due to channel contention from multiple interrupted secondary connections [3].

The PRP M/G/1 queuing model organizes channels in queues; Secondary Connections are arranged in lowpriority queues when Primary Connections are in highpriority queues. The Primary Connections have the preemptive right to access and transmit in the channel. Meanwhile Secondary Connections use the idleness of the channel to transmit. During their transmission, Secondary Connections endure multiple Primary Connections interruptions and Spectrum Handoff Sequences are defined according to Secondary Connections behavior towards those interruptions. In this paper we propose a novel Spectrum Handoff Sequence. Next, to show the efficiency of our novel Spectrum Handoff Sequence, we propose a novel performance metric that we call Lifetime of Secondary Connections instead of the Extended Data Delivery Time of Secondary Connections and we use it to compare the IEEE 802.22 Spectrum Handoff Sequences standards with our propose Spectrum Handoff Sequence. In our analysis, to prove the importance of the Lifetime metric, we will take the first four Secondary Connections present in a low-priority queue, analyze the first Secondary Connection Extended Data Delivery Time and deduce the effect on the Lifetime of the other three Secondary Connections. We will see that our proposed sequence is a better Spectrum Handoff Sequence, and that the Lifetime of Secondary Connections brings new system analysis that improves considerably the cognitive radio handoff performance.

\section{IEE 802.22 STANDARDS FOR SPECTRUM HANDOFF SEQUENCES}

Spectrum handoff in cognitive wireless networks impacts directly on software and hardware costs of system resources, and it is critical to design and evaluate the strategy of wireless resources management [4]. When a Primary Connection appears, current channel condition becomes worse causing spectrum mobility to arise. Due to 
this a chain reaction is triggered and spectrum mobility also causes spectrum handoff to arise. Figure 1 shows spectrum mobility and spectrum handoff processes. From what precedes, it appears that it is important to describe efficient spectrum handoff sequences. These will follow the analyzing network model to create policy that will be applied to coexisting Secondary Connections.

Here, we will briefly introduce spectrum handoff sequences provided by the IEEE 802.22 standards, while give the main limitation of each one.

-The always-staying sequence: Here a Secondary Connection always stays on its default channel $\eta$ at every interruption. That is, the other Secondary Connections in low-priority queues will have to wait an infinite time before transmitting. Though the lack of fairness.

-The always-leaving sequence: Here, a Secondary Connection will switch to a different channel at each interruption. With the channel switching delay and the residual service time to consider, this sequence shows an enormous effective service time

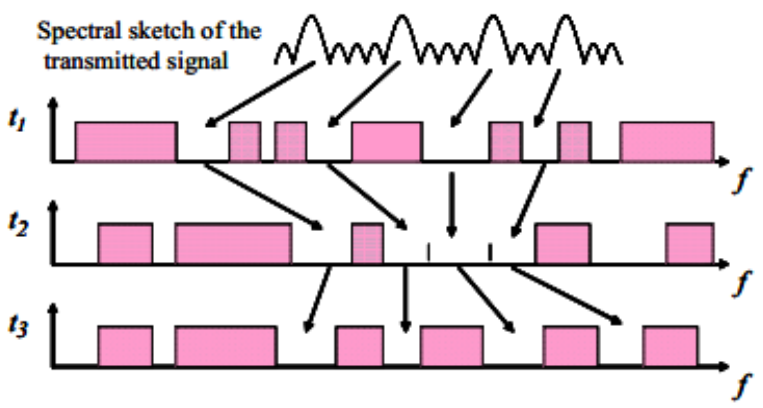

Figure1. Spectrum mobility and spectrum handoff process

\section{EXTENDED DATA DELIVERY TIME OF OUR PROPOSED SEQUENCE}

In our proposed sequence, a Secondary Connection will endure a predefined number $(\mathrm{Ni})$ of interruptions on a channel $\mathrm{k}$, and then switches to another target channel where it will occupy the head of the low priority queue after the ongoing connection terminates. We assume the expression of the Average Extended Data Delivery Time defined in [3] as the basis of our analysis. In table (1) there is a resume of important notations that we will use in what will follow. In general, a Secondary Connection that encounters $\mathrm{N}$ interruptions has an average Extended Data Delivery Time of:

$\mathrm{E}[\mathrm{T}]=\sum_{\mathrm{n}=1}^{\mathrm{n}_{\max }} \mathrm{E}[\mathrm{T} \mid \mathrm{N}=\mathrm{n}] \operatorname{Pr}(\mathrm{N}=\mathrm{n})$

By definition, the Extended Data Delivery Time is the original service time added to the cumulative handoff delay of the Secondary Connection. Here, a Secondary Connection can eventually endure $\mathrm{Ni}+1$ interruptions, in which case we will consider the handoff delay for the case it will stay Ni times on a channel, and the one when it will switch to another channel at the $\mathrm{Ni}+1$ interruption. We can then write the Extended Data Delivery Time of the considered Secondary Connection as:

$\mathrm{E}[\mathrm{T} \mid \mathrm{N}=\mathrm{n}]=\mathrm{E}\left[\mathrm{Xs}{ }^{(\mathrm{k})}\right]+\mathrm{E}\left[\mathrm{T}_{1}\right]+\mathrm{E}\left[\mathrm{T}_{2}\right]$

Where $E\left[T_{1}\right]$ and $E\left[T_{2}\right]$ represent the staying ( $\mathrm{Ni}$ times) part and switching part successively. With the general form of:

$\mathrm{E}\left[\mathrm{T}_{1 / 2}\right]=\sum_{\mathrm{i}=1}^{\mathrm{n}} \mathrm{E}\left[\mathrm{D}_{\mathrm{i}(1 / 2)}\right]$

In what follow, we will consider two channels $\mathrm{k}$ and $\mathrm{k}$. Here $\mathrm{k}$ is the current channel in which the Secondary Connection being served may endure $\mathrm{Ni}$ interruptions; and k' the channel where the Secondary Connection will switch at the $(\mathrm{Ni}+1)^{\text {th }}$ interruption.

Let's first derive $E\left[D_{i(1)}\right]$. When the considered Secondary Connection stays on the same channel, the handoff delay is the busy probability resulting from multiple Primary Connections of channel $\mathrm{k}$ denoted as $\mathrm{Yp}^{(\mathrm{k})}$. That is, $\mathrm{E}\left[\mathrm{D}_{\mathrm{i}(1)}\right]=\mathrm{E}\left[\mathrm{Yp}^{(\mathrm{k})}\right]$. The Secondary Connection using the idleness of the channel to transmit, its Extended Data Delivery Time can be expressed from the memory less property applied to the idle period as in [5], as:

$\mathrm{E}\left[\mathrm{Ip}^{(\mathrm{k})}\right]=\frac{1}{\lambda_{\mathrm{p}}^{(\mathrm{k})}}$

From the utilization factor of channel $\mathrm{k}$ we have:

$\rho_{\mathrm{i}}^{(\mathrm{k})}=\lambda_{\mathrm{p}}^{(\mathrm{k})} \mathrm{E}\left[\left(\mathrm{X}_{\mathrm{p}}^{(\mathrm{k})}\right)\right]$

$\rho_{\mathrm{i}}^{(\mathrm{k})}$ Being the channel busy probability from the Primary Connections, we have:

$\rho_{\mathrm{i}}^{(\mathrm{k})}=\frac{\mathrm{E}\left[\mathrm{Yp}^{(\mathrm{k})}\right]}{\mathrm{E}\left[\mathrm{Yp}^{(\mathrm{k})}\right]+\mathrm{E}\left[\mathrm{Ip}^{(\mathrm{k})}\right]}$

Then replace (4) and (5) into (6):

$\mathrm{E}\left[\mathrm{Yp}^{(\mathrm{k})}\right]=\frac{\mathrm{E}\left[\mathrm{Xs}^{(\mathrm{k})}\right]}{1-\rho_{\mathrm{p}}^{(\mathrm{k})}}=\frac{\mathrm{E}\left[\mathrm{Xs}^{(\mathrm{k})}\right]}{1-\lambda_{\mathrm{p}}^{(\mathrm{k})} \mathrm{E}\left[\left(\mathrm{X}_{\mathrm{p}}^{(\mathrm{k})}\right)\right]}$

Next, the Secondary Connection will switch to a different channel and wait only until the current connection finishes. Its handoff delay will then be the channel switching delay time added to the average effective residual time of channel k'.

If we note $\mathrm{E}\left[\mathrm{Wp}^{\left(\mathrm{k}^{\prime}\right)}\right]$ as the waiting time in channel $k^{\prime}$ we have $E\left[W p^{\left(k^{\prime}\right)}\right]=E\left[R_{s}{ }^{\left(k^{\prime}\right)}\right]$. 
$\mathrm{E}\left[\mathrm{R}_{\mathrm{s}}{ }^{\left(\mathrm{k}^{\prime}\right)}\right]$ Serves as the remaining time to complete the service of the connection being served at channel k'[6]. Considering the channel switching delay, we can have the final expression of the handoff delay as:

$\mathrm{E}\left[\mathrm{D}_{\mathrm{i}(2)}\right]=\mathrm{E}\left[\mathrm{R}_{\mathrm{s}}{ }^{\left(\mathrm{k}^{\prime}\right)}\right]+\mathrm{ts}$

With the definition of the residual time in [3] we have:

$\mathrm{E}\left[\mathrm{R}_{\mathrm{s}}{ }^{\left(\mathrm{k}^{\prime}\right)}\right]=\frac{1}{2} \lambda_{\mathrm{p}}^{\left(\mathrm{k}^{\prime}\right)} \mathrm{E}\left[\left(\mathrm{X}_{\mathrm{p}}^{\left(\mathrm{k}^{\prime}\right)}\right)^{2}\right]+\mathrm{w}_{\mathrm{i}}^{\left(\mathrm{k}^{\prime}\right)} \mathrm{E}\left[\left(\Phi_{\mathrm{i}}^{\left(\mathrm{k}^{\prime}\right)}\right)^{2}\right]$

Note that the ongoing connection can be either from Secondary Connections or Primary Connections. Then comes the derivation of $\operatorname{Pr}(\mathrm{N}=\mathrm{n})$. In any case (staying or leaving), here we consider the channel sequence $\left(S_{1, \eta}, S_{2, \eta}, S_{3, \eta}, \ldots, S_{i, \eta}\right)$ with $S_{i, \eta}=\eta$ as the default channel. The probability that the Secondary Connection is interrupted again at the ith interruption is defined as $p_{i}^{(k)}$. That gives us the general expression of $\operatorname{Pr}(\mathrm{N}=\mathrm{n})$ as:

$\operatorname{Pr}(N=n)=\left(1-p_{n}^{\left(S_{n}, n\right)}\right) \prod_{i=0}^{n-1} p_{i}^{\left(S_{i, n}\right)}$

We can then obtain the final expression of our proposed sequence Extended Data Delivery Time from (1), (2), (7), (8),(9) and (10) as :

$$
\begin{aligned}
& \mathrm{E}\left[\mathrm{T}_{\mathrm{f}}\right]=\mathrm{E}\left[\mathrm{Xs}^{(\mathrm{k})}\right]+\sum_{\mathrm{n}=1}^{\mathrm{Ni}}\left[\left(\sum_{\mathrm{i}=1}^{\mathrm{n}} \mathrm{E}\left[\mathrm{Yp}^{(\mathrm{k})}\right]\right)\left(1-\mathrm{p}_{\mathrm{i}}^{(\mathrm{k})}\right) \prod_{\mathrm{i}=0}^{\mathrm{Ni}-1} \mathrm{p}_{\mathrm{i}}^{(\mathrm{k})}\right]+ \\
& \sum_{\mathrm{n}=1}^{\mathrm{N}}\left[\left(\sum_{\mathrm{i}=1}^{\mathrm{n}}\left(\frac{1}{2} \lambda_{\mathrm{p}}^{\left(\mathrm{k}^{\prime}\right)} \mathrm{E}\left[\left(\mathrm{X}_{\mathrm{p}}^{\left(\mathrm{k}^{\prime}\right)}\right)^{2}\right]+\frac{1}{2} \sum_{\mathrm{i}=0}^{\mathrm{n}_{\max }} \mathrm{w}_{\mathrm{i}}^{\left(\mathrm{k}^{\prime}\right)} \mathrm{E}\left[\left(\Phi_{\mathrm{i}}^{\left(\mathrm{k}^{\prime}\right)}\right)^{2}\right]+\mathrm{ts}\right)\right]\right.
\end{aligned}
$$

With

$\mathrm{w}_{\mathrm{i}} \mathrm{E}\left[\left(\Phi_{\mathrm{i}}\right)^{2}\right]=\lambda_{\mathrm{s}}\left(\frac{\lambda_{\mathrm{p}}}{\lambda_{\mathrm{p}}+\mu_{\mathrm{s}}}\right)^{\mathrm{i}} \frac{2}{\left(\lambda_{\mathrm{p}}+\mu_{\mathrm{s}}\right)^{2}}$

Table 1: NOTATIONS

\begin{tabular}{|c|l|}
\hline$\lambda_{p}^{(\eta)}$ & $\begin{array}{l}\text { Traffic arrival rate of the PRIMARY CONNECTIONs at } \\
\text { channel } \eta\end{array}$ \\
\hline$\lambda_{s}^{(\eta)}$ & $\begin{array}{l}\text { Initial traffic arrival rate of the Secondary Connections at } \\
\text { default channel } \eta\end{array}$ \\
\hline $\mathrm{X}_{p}^{(\eta)}$ & $\begin{array}{l}\text { Service time of the PRIMARY CONNECTIONs at channel } \\
\eta\end{array}$ \\
\hline $\mathrm{X}_{s}^{(\eta)}$ & $\begin{array}{l}\text { Service time of the Secondary Connections at default } \\
\text { channel } \eta\end{array}$ \\
\hline$t_{s}$ & Channel switching time \\
\hline$D_{i}$ & Handoff delay for the ith interruption \\
\hline$n_{\max }$ & $\begin{array}{l}\text { Maximum number of interruptions for the Secondary } \\
\text { Connections }\end{array}$ \\
\hline$S_{i, n}$ & The target channel at the ith interruption \\
\hline$p_{i}^{\left(S_{n, n}\right)}$ & $\begin{array}{l}\text { Interrupted probability when the Secondary Connection has } \\
\text { experienced i interruptions }\end{array}$ \\
\hline
\end{tabular}

Here, we have the simulation Comparison between our proposed sequence and the IEEE 802.22 Spectrum Handoff Sequence standards using the Extended Data Delivery Time metric with $t s=1, \lambda \mathrm{s}=0.01, \mathrm{E}[\mathrm{Xs}]=10$, and $\mathrm{E}[\mathrm{Xp}]=20$.

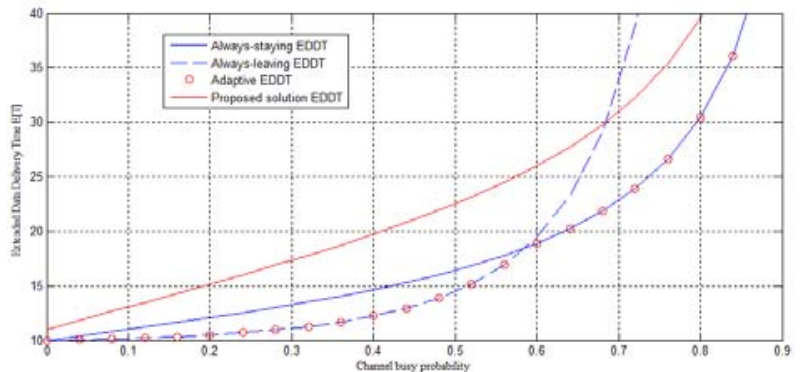

Figure2. Analysis of Spectrum Handoff Sequences using the Extended Data Delivery Time

Figure 2 shows simulation results of the comparison between our proposed sequence and the IEEE 802.22 Spectrum Handoff Sequences standards using the Extended Data Delivery Time. Here, the adaptive sequence adopts the better channel sequence between the always-leaving and always-staying sequences, to reduce its Extended Data Delivery Time. It is expressed as:

$\mathrm{E}\left[\mathrm{T}^{*}\right]=\min \left(\mathrm{E}\left[\mathrm{T}_{\text {stay }}\right], \mathrm{E}\left[\mathrm{T}_{\text {leave }}\right]\right)$

In the next simulations, we will use the adaptive model as standards comparison because it regroups at anytime the best values of the always-leaving and always-staying sequences. Here, it is represented by red circles.

\section{NOVEl METRIC DEFINITION: LifETIME TO ANALYZE SECONDARY CONNECTIONS}

The Lifetime of secondary connection evaluates latency-sensitive traffic of Secondary Connections. We define the Lifetime of Secondary Connections as the interval of time needed by any considered Secondary Connection from the moment it enters a queue until it finishes or terminates its transmission.

The lifetime studies any connection before they even start transmitting in any queue of any channel. This aspect of study joins cognitive radio capability to add prevision in our proposed metric. That distinguishes the Lifetime metric from the Extended Data Delivery Time metric. In what follows, we will evaluate the Lifetime of secondary connections in three precise cases: always-leaving, alwaysstaying and our proposed sequence. In what follows, let's denote $E\left[\mathrm{~T}_{\text {trans }}^{\mathrm{j}}\right]$ as the transmission duration of the $\mathrm{j}^{\text {th }}$ secondary user, and $\mathrm{LF}\left[\mathrm{T}_{\text {trans }}^{\mathrm{j}}\right]$ the $\mathrm{j}^{\text {th }}$ Secondary Connection Lifetime.

- Case1

In the always-staying sequence, the first Secondary Connection will not leave the queue until it finishes or terminates its transmission. Therefore, the queued Secondary Connections lifetime will be their own transmission duration added to the ones above them.

$\mathrm{LF}\left[\mathrm{T}_{\text {trans }}^{\mathrm{j}}\right]=\mathrm{E}\left[\mathrm{T}_{\text {trans }}^{\mathrm{j}}\right]+\sum_{\mathrm{j}=0}^{\mathrm{n}} \mathrm{E}\left[\mathrm{T}_{\text {trans }}^{\mathrm{j}}\right]$ 
Here $\mathrm{E}\left[\mathrm{T}_{\text {trans }}^{\mathrm{j}}\right]=\mathrm{E}[\mathrm{T} 1]$ and ' $\mathrm{n}$ ' is number of Secondary Connections above the considered Secondary Connection.

\section{- $\quad$ Case2}

In the always-leaving sequence, each Secondary Connection will operate channel switching at each handoff with a waiting time of $\left[\mathrm{Rs}^{\left(\mathrm{k}^{\prime}\right)}\right]$, as cited above:

$\mathrm{LF}\left[\mathrm{T}_{\text {trans }}^{\mathrm{j}}\right]=\mathrm{E}\left[\mathrm{T}_{\text {trans }}^{\mathrm{j}}\right]+\sum_{\mathrm{j}=0}^{\mathrm{n}}\left(\mathrm{E}\left[\mathrm{Rs}^{\left(\mathrm{k}^{\prime}\right)}\right]^{\mathrm{j}}\right)$

Where $\mathrm{E}\left[\mathrm{T}_{\text {trans }}^{\mathrm{j}}\right]=\mathrm{E}[\mathrm{T} 2]$

- Case3

In our proposed Spectrum Handoff Sequence, the first Secondary Connection will leave after $\mathrm{Ni}$ interruptions:

$\mathrm{LF}\left[\mathrm{T}_{\text {trans }}^{\mathrm{j}}\right]=\mathrm{E}\left[\mathrm{T}_{\text {trans }}^{\mathrm{j}}\right]+\sum_{\mathrm{j}=0}^{\mathrm{n}}\left(\mathrm{Y}^{\mathrm{j}}\right)$

Here, $\mathrm{E}\left[\mathrm{T}_{\text {trans }}^{\mathrm{j}}\right]=\mathrm{E}[\mathrm{Tf}]$

And,

$\mathrm{Y}=\sum_{\mathrm{n}=1}^{\mathrm{Ni}}\left(\sum_{\mathrm{i}=1}^{\mathrm{n}} \mathrm{E}\left[\mathrm{Yp}^{(\mathrm{k})}\right]\right)\left(1-\mathrm{p}_{\mathrm{i}}^{(\mathrm{k})}\right) \prod_{\mathrm{i}=0}^{\mathrm{Ni}-1} \mathrm{p}_{\mathrm{i}}^{(\mathrm{k})}$

The values of E [T1], E [T2] and E [Tf] have been studied in the previous section. Note that the alwaysleaving and always-staying sequences and derivations are already been analyzed in [3].

Figure 3 shows Lifetime metric when analyzing Spectrum Handoff Sequences. Here, our proposed solution renders four Secondary Connections completely served with a maximum Lifetime less than 25(time/slot) as illustrated in figure 3 . It also allows the $10^{\text {th }}$ Secondary Connection to be serviced within the same interval. On the contrary, in related spectrum handoff sequences analysis, the Lifetime values of the first four considered Secondary Connections will have lifetime values between 25 and 30 (time/slot). This illustrates that our proposed Spectrum Handoff Sequence is not only efficient but also fair because the policy used satisfies the maximum of Secondary Connections in a short time. However, this outcome can only be seen when using the Lifetime metric instead of the Extended Data Delivery Time. This shows the important contribution of our metric in Spectrum Handoff Sequence implementation. Furthermore, the $10^{\text {th }}$ Secondary Connection in actual Spectrum Handoff Sequences will need an infinite Lifetime to be served. This shows that the performance of our proposed Spectrum Handoff Sequence grows with channel busy probability

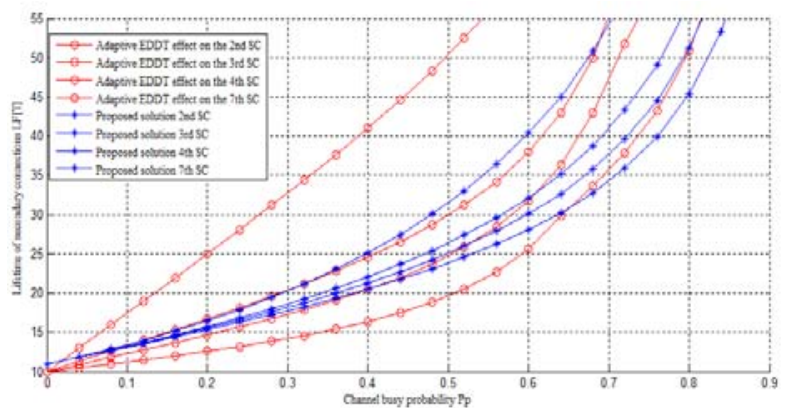

Figure 3. Analysis of Spectrum Handoff Sequences using the lifetime of Secondary Connection

\section{CONCLUSION}

We used the PRP M/G/1 queuing model, and designed a novel Spectrum Handoff Sequence to improve handoffs in cognitive radio networks. Additionally, we compare our proposed solution with the existing sequences using the extended data delivery time and next the novel metric that we proposed. From this method it is concluded that our proposed Spectrum Handoff Sequence provides a solution of both fairness and efficiency. Furthermore, the Lifetime of Secondary Connections allows us to predetermine our cognitive radio network system performance, while modeling novel Spectrum Handoff Sequences.

\section{ACKNOWLEDGMENT}

This work was supported by the Natural Science Foundation of Jilin Province of China under Grant No. 201215133.

\section{REFERENCES}

[1]. H.-J. Liu, Z.-X. Wang, S.-F. Li, and M. Yi, "Study on the Performance of Spectrum Mobility in Cognitive Wireless Network," IEEE International Conference on Communication Systems (ICCS), pp. 123-456) Jun. 2008.

[2]. Anita Garhwal and Partha Pratim Bhattacharya., "A Survey on Dynamic Spectrum Access Techniques for Cognitive Radio, " International Journal of Next-Generation Networks (IJNGN) Vol.3, No.4, December 2011.

[3]. L. C. Wang, C. W. Wang and C. J. Chang, "Modeling and Analysis for Spectrum Handoffs in Cognitive Radio Networks," IEEE Trans.Mobile Computing, vol. 12, no. 3, pp. 456-789, July 2011.

[4]. Hong-jie LIU, Zhong-xu WANG, Shu-fang LI, Min YI, "Study on the Performance of Spectrum Mobility in Cognitive Wireless Network, " ICCS 2008

[5]. Chee-Hock Ng and Boon-Hee Soong, Queueing "Modelling Fundamentals with Applications in Communication Networks," 2nd. John Wiley \& Sons Inc., 2008

[6]. S. K. Bose, "An Introduction to Queueing Systems, "Kluwer Academic/Plenum Publishers, New York, 2002 